\title{
Polypyrrole/TiO 2 Nanotube Arrays with Coaxial Heterogeneous Structure as Sulfur Hosts for Lithium Sulfur Batteries
}

\author{
Yun Zhao ${ }^{\mathrm{a}, \mathrm{d}}$, Wen Zhu* ${ }^{*, \mathrm{a}, \mathrm{b}, \mathrm{d}}$, George Z. Chen*,b, and Elton J. Cairns*,c

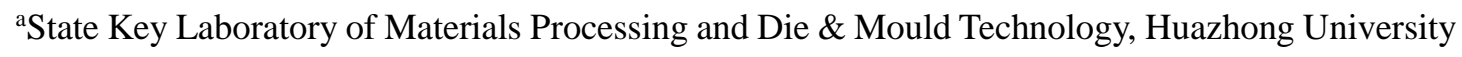 \\ of Science \& Technology, Wuhan 430074, People's Republic of China. \\ ${ }^{b}$ Department of Chemical and Environmental Engineering, University of Nottingham, Nottingham \\ NG72RD, UK \\ ${ }^{\mathrm{c} D e p a r t m e n t}$ of Chemical and Biomolecular Engineering, University of California, Berkeley, \\ California 94720, United States \\ ${ }^{\mathrm{d}}$ Research Institute of Huazhong University of Science \& Technology in Shenzhen, Shenzhen \\ Virtual University Park, Shenzhen 518000, People's Republic of China \\ *To whom correspondence should be addressed. E-mail address: wen.zhu@nottingham.ac.uk (W. Z.); \\ george.chen@nottingham.ac.uk (G.Z.C.); ejcairns@lbl.gov (E.J.C.)
}

\begin{abstract}
The lithium-sulfur cell has shown great prospects for future energy conversion and storage systems due to the high theoretical specific capacity of sulfur, $1675 \mathrm{mAh} \mathrm{g}^{-1}$. However, it has been hindered by rapid capacity decay and low energy efficiency. In this work, polypyrrole (PPy)/TiO 2 nanotubes with coaxial heterogeneous structure as the substrate of the cathode is prepared and used to improve the electrochemical performance of sulfur electrodes. $\mathrm{TiO}_{2}$ nanotubes decorated with PPy provide a highly ordered conductive framework for $\mathrm{Li}^{+}$ion diffusion and reaction with sulfur. This architecture also is helpful for trapping the produced polysulfides, and as a result attenuates the capacity decay. Furthermore, the heat treatment temperature used in the sulfur loading process has been confirmed to have an important impact on the overall performance of the resultant cell. The as-designed $\mathrm{S} / \mathrm{PPy} / \mathrm{TiO}_{2}$ nanotube cathode using an elevated heating temperature shows excellent
\end{abstract}


cycling stability with a high discharge capacity of $1150 \mathrm{mAh} \mathrm{g}^{-1}$ and average coulombic efficiency of $96 \%$ after 100 cycles.

Keywords: coaxial heterogeneous structure; lithium batteries; sulfur; Polypyrrole; $\mathrm{TiO}_{2}$ nanotubes

\section{Introduction}

Along with the advancement of human industrialization, the demand for energy has shown an increase year after year, which has made energy storage technology more important than at any time[1]. Batteries, especially the lithium battery, which has been industrialized and widely used in portable electronic devices, has played a pivotal role among numerous energy storage technologies[2]. However, apart from the safety issue, the fact that the Li-ion battery is near its performance limit makes it more urgent for people to find a more promising successor[3, 4]. Li-S cells have received much attention since they were first reported in 1962 by Herbet and Ulam[5], and then gained ever-increasing attention after Nazar et al. reported a high specific capacity Li-S cell with good cycling performance based on CMK-3[6]. A conventional Li-S cell operates based on the redox reaction between sulfur and lithium to form lithium sulfide $\left(\mathrm{Li}_{2} \mathrm{~S}\right)$ described as $\mathrm{S}_{8}+$ $16 \mathrm{Li} \leftrightarrow 8 \mathrm{Li}_{2} \mathrm{~S}$. If this redox reaction is reversible and complete, a very high theoretical capacity of $1675 \mathrm{~mA} \mathrm{~h} \mathrm{~g}^{-1}$ will be achieved[7, 8]. Moreover, the abundance, low toxicity and low cost of sulfur as the cathode material make the Li-S cell a qualified candidate as a cheap, eco-friendly and longlasting rechargeable cell with high performance[9-11].

However, despite the aforementioned advantages, Li-S cells are plagued with several issues that have hindered commercialization. First, sulfur, which is an insulating material $\left(5 \times 10^{-30} \mathrm{~S} \mathrm{~cm}^{-1}\right.$ at 25 ${ }^{\circ} \mathrm{C}$ ), cannot be directly used as the electrode. It is necessary to use conductive additives to the 
cathode, which is at the expense of a lower amount of the active substance in the cathode[12, 13]. Secondly, the dissolution of lithium polysulfides (PS) formed as intermediates of the conversion reaction from sulfur to lithium sulfide into the organic liquid electrolyte leads to the loss of active substance, and causes the so-called polysulfide shuttling effect when the soluble lithium polysulfides freely migrate between the cathode and anode where adverse reactions occur[1]. Besides, a large volume expansion ( $76 \%$ ) of sulfur originating from the density difference between sulfur and $\mathrm{Li}_{2} \mathrm{~S}$ during charge and discharge process is also a problem that can't be neglected[14].

Over the years, plenty of research focused on the above-mentioned problems has been done to improve the cycling performance of Li-S cells. A variety of cathode structures have been designed to trap PS to mitigate the "shuttling effect" or reduce the damage caused by the volume expansion. The common method is the combination of sulfur with conductive carbon additives, such as porous carbon with different pore sizes[15], hollow carbon spheres[16], graphene[13, 17], carbon nanotubes[18] and nanofibers[12]. Due to their high electrical conductivity along with sensibly designed framework to confine sulfur, trap soluble PS and eliminate volume expansion, these carbon materials have shown great improvements during the past decade. Besides, conductive polymers such as polypyrrole (PPy)[19-21], polyaniline (PANI)[22] and poly(3,4-(ethylenedioxy)thiophene) (PEDOT)[23] have also played a significant role in $\mathrm{Li}-\mathrm{S}$ cells because of their elastic long chain structure, special functional groups and strong chemical bonds with sulfur. $\mathrm{TiO}_{2}$, as an inorganic material, is technically competent as a host for sulfur, but always was limited by its small surface area and pore volume until a sulfur- $\mathrm{TiO}_{2}$ yolk-shell nanoarchitecture proposed by $\mathrm{Cui}$ and coworkers[24]. This delicately designed structure represents a significant advance for long-cycle lithium-sulfur cells over 1,000 cycles with coulombic efficiency of $98.4 \%$. Since then, many works 
have been reported on $\mathrm{TiO}_{2}$ as a promising candidate material for use in lithium sulfur cells[25-27].

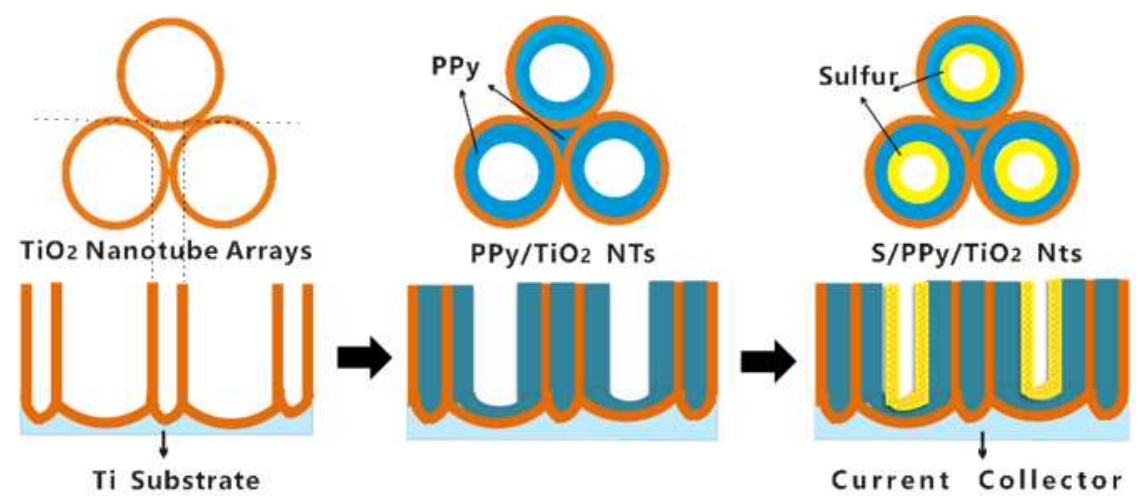

Fig. 1. Schematic illustration for the synthesis of $\mathrm{S} / \mathrm{PPy} / \mathrm{TiO}_{2} \mathrm{NTs}$ composite with coaxial heterogeneous structure

Herein, we report a polypyrrole/ $/ \mathrm{TiO}_{2}$ nanotube array with coaxial heterogeneous structure as a sulfur host for lithium-sulfur cells. As illustrated in Fig. 1, the highly ordered $\mathrm{TiO}_{2}$ nanotube arrays (NTs) are prepared by a two-step anodization method. Then PPy layers are grown along the wall of the nanotubes by electrochemical deposition. The nanotube array cathode with coaxial heterogeneous structure is obtained after loading sulfur plus subsequent heat treatment. In this structure, the $\mathrm{TiO}_{2}$ NTs as a highly ordered substrate with large specific surface area host abundant sulfur and absorb PS to some extent, while the PPy layers along the tube wall further enhance the conductivity and stabilize the coaxial heterogeneous structure during the charge/discharge process. Moreover, PPy layers can form strong chemical bonds with sulfur and restrain the escape of PS from the tube. The huge tube space and the soft polymer layer can also accommodate the volume change during cycling. Herein, the coaxial heterogeneous structure will be expected to exhibit an excellent electrochemical performance, and the influence of different heat treatment temperatures in the sulfur loading process will be reported.

\section{Experimental}

2.1 Preparation of highly ordered $\mathrm{TiO}_{2} \mathrm{NTs}$ 
Highly ordered $\mathrm{TiO}_{2}$ NTs were prepared by a two-step anodization method. Prior to anodization, the pure titanium foils ( $0.2 \mathrm{~mm}$ thick, $60 \mathrm{~mm} \times 10 \mathrm{~mm}, 99.8 \%$ purity) were ultrasonically cleaned in order with acetone, deionized water and ethanol for $15 \mathrm{~min}$ each, and then dried in a nitrogen stream. A two-electrode configuration with titanium foil as the working electrode and platinum foil as the counter electrode was used for the anodization, which was carried out under constant potential (54 V) at water-bath temperature, approximately $30{ }^{\circ} \mathrm{C}$. The electrolyte was an organic mixture containing 0.32 wt. $\% \mathrm{NH}_{4} \mathrm{~F}$ and 2.0 vol. \% distilled $\mathrm{H}_{2} \mathrm{O}$ dissolved in ethylene glycol. The first step was performed by anodizing the titanium foils for $20 \mathrm{~min}$, followed by a heat treatment at $700{ }^{\circ} \mathrm{C}$ for $1 \mathrm{~h}$ with a heating rate of $7^{\circ} \mathrm{C} \mathrm{min}^{-1}$ to form a compact rutile layer on the foil surface. The second anodization altered the anodization time to $8 \mathrm{~h}$, and then the samples were annealed again at $300{ }^{\circ} \mathrm{C}$ for $2 \mathrm{~h}$ with heating rate of $3{ }^{\circ} \mathrm{C} \mathrm{min}^{-1}$.

\subsection{Preparation of $\mathrm{PPy} / \mathrm{TiO}_{2}$ NTs}

The $\mathrm{PPy} / \mathrm{TiO}_{2}$ NTs were obtained by electrochemically depositing pyrrole on the as-prepared highly ordered $\mathrm{TiO}_{2}$ NTs in aqueous pyrrole solution containing $0.1 \mathrm{M}$ pyrrole monomer, $0.2 \mathrm{M}$ Sodium p-toluenesulfonate (TsONa, Sigma-Aldrich) and deionized water at pH 2 4 adjusted with $\mathrm{HCl}$. Deposition was carried out in a three-electrode cell, in which a saturated calomel electrode (SCE) was used as reference electrode, a platinum foil served as counter electrode, and the asprepared $\mathrm{TiO}_{2} \mathrm{NTs}$ were the working electrodes. The electrodeposition procedure was performed using a computer controlled electrochemical workstation (CS310, CorrTest Instrument Co., Ltd, Wuhan) that was connected to the three-electrode cell at room temperature. The PPy membranes were galvanostaticallly polymerized along the wall of the $\mathrm{TiO}_{2}$ nanotubes with a constant current density of $1.0 \mathrm{~mA} \mathrm{~cm}^{-2}$ for $15 \mathrm{~min}$. Then the resultant $\mathrm{PPy} / \mathrm{TiO}_{2} \mathrm{NTs}$ were washed well with distilled 
water and dried in an air dry oven for use as the substrate for the sulfur cathode.

\subsection{Sulfur loading}

For comparison, both the as-prepared pure $\mathrm{TiO}_{2} \mathrm{NTs}$ and $\mathrm{PPy} / \mathrm{TiO}_{2} \mathrm{NTs}$ were used as the substrate for sulfur. The substrate was first soaked in a $1 \%$ sulfur solution in toluene for $10 \mathrm{~h}$ to make sure that the solution was fully filled into each tube. Then the dissolved sulfur in toluene was deposited inside the tube after removing the toluene solvent in an air dry oven. According to the deposition amount of PPy and the weight of sulfur, the estimated C-S ratio is 1:1.5 in the whole sulfur cathode. The preprocessed substrate was sealed inside a small vessel under argon to create a closed condition for sulfur impregnating. The sealed vessel was placed into the vacuum-sealed quartz tube and heated using various temperatures. Samples of $\mathrm{S} / \mathrm{PPy} / \mathrm{TiO}_{2} \mathrm{NTs}-160$ were obtained by using the heat treatment temperature at $160{ }^{\circ} \mathrm{C}$ for $10 \mathrm{~h}$ with $\mathrm{PPy} / \mathrm{TiO}_{2} \mathrm{NTs}$ as the substrate. Samples of $\mathrm{S} / \mathrm{TiO}_{2}$ NTs without PPy suffered the same heat treatment but with the pure $\mathrm{TiO}_{2} \mathrm{NTs}$ as the substrate. Samples of S/PPy/TiO 2 NTs-300 were obtained by further heating the S/PPy/ $\mathrm{TiO}_{2} \mathrm{NTs}-160$ to 300 ${ }^{\circ} \mathrm{C}$ for $2 \mathrm{~h}$. After that, all of the samples were put into a high temperature chamber that has a constant temperature condition around $180^{\circ} \mathrm{C}$ to remove the remained sulfur on the surface of the substrate.

\subsection{Materials characterization}

The morphology, microstructure and element components of as-prepared cathode materials were observed by field emission scanning electron microscopy (FE-SEM, Sirion 200), field emission transmission electron microscopy (FE-TEM, Tecnai G2 F30) and energy dispersive X-ray spectroscopy (EDS, GENESIS). The line scanning was conducted by STEM-EDX with a HAADF detector on TEM (JEOL, JEM-2100F) operated at $200 \mathrm{kV}$. The phase of composites were characterized by X-ray diffraction (XRD, X Pert PRO) using $\mathrm{Cu} \mathrm{K \alpha}$ radiation $(\lambda=0.15406 \mathrm{~nm})$ from 
$20^{\circ}$ to $70^{\circ}$. Chemical bonds of materials were investigated by Fourier transform infrared spectroscopy (FT-IR, VERTEX 70) and Raman spectroscopy (LabRAM HR800) with laser wavelength of $532 \mathrm{~nm}$. Content of sulfur in cathode materials was determined by thermogravimetric analysis (TG, Pyrisl TGA) in the temperature range of $40-500{ }^{\circ} \mathrm{C}$ at a heating rate of 10 ${ }^{\circ} \mathrm{C} \min ^{-1}$ under a $\mathrm{N}_{2}$ atmosphere.

2.5 Assembly and tests of batteries

The electrochemical performances of materials were investigated by testing the assembled coin cells with the nanotube arrays as the cathode, lithium foils as the anode and microporous polypropylene film (Celgard 2300) as the separator. Since the underlying titanium metal layer can act as a cathode current collector, the as-prepared $\mathrm{S} / \mathrm{TiO}_{2} \mathrm{NTs}$ and $\mathrm{S} / \mathrm{PPy} / \mathrm{TiO}_{2} \mathrm{NTs}$ can be used as the cathode directly without any dispersant or binder. The mass density of active substance sulfur was determined by weighing to be about $1.8-2.2 \mathrm{mg} \mathrm{cm}^{-2}$. Coin cells (CR2032) were assembled in an argon-filled glovebox (Lab2000). The electrolyte consisted of lithium bis(trifluoromethanesulfonyl)imide $\left(1 \mathrm{~mol} \mathrm{dm}^{-3}\right)$ as solute and a mixture of 1, 3-dioxolane (DOL) and 1, 2dimethoxyethane (DME) (1:1 by volume) as solvent with $0.2 \mathrm{~mol} \mathrm{dm}^{-3} \mathrm{LiNO}_{3}$ as an additive. The assembled cells were galvanostatically charged and discharged between 1.8 and $3.0 \mathrm{~V}$ versus $\mathrm{Li}^{+} / \mathrm{Li}$ by LAND CT2001A battery test system. The current rates and specific capacity of the cells were calculated based on the mass of sulfur in the cathodes. Cyclic voltammetry was carried out in a range from 1.8 to $3 \mathrm{~V}$ versus $\mathrm{Li}^{+} / \mathrm{Li}$ using a scanning rate of $0.1 \mathrm{mV} \mathrm{s}^{-1}$.

\section{Results and discussion}

Field emission scanning electron microscopy (FE-SEM) was used to characterize the top surface 
of the well-ordered nanotube structures. Fig. 2a shows the FE-SEM image of the pure $\mathrm{TiO}_{2} \mathrm{NTs}$ with a uniform inner tube diameter of $\sim 120 \mathrm{~nm}$. As shown in Fig. 2a, the wall thickness of nanotubes is only about few nanometers, implying the $\mathrm{TiO}_{2} \mathrm{NTs}$ can offer a large space for PPy deposition and sulfur loading. The side view of pure $\mathrm{TiO}_{2}$ nanotube arrays displayed in Fig. S1 reveals the nanotube length of $\sim 20 \mu \mathrm{m}$. Fig. $2 \mathrm{~b}$ is the morphology of $\mathrm{PPy} / \mathrm{TiO}_{2} \mathrm{NTs}$. The array structure is maintained well after PPy deposition, while the tube walls become thicker and the voids between arrays are filled with polymer. As is displayed in the Fig. 1, the growth of the PPy is conducted both inside and outside of the tubes simultaneously. After being coated a monolayer onto the surface of $\mathrm{TiO}_{2}$ tube walls, the PPy films will continue to grow against the tube walls. Since the inner diameter of $\mathrm{TiO}_{2}$ NTs are larger than the voids between tubes, the voids between tubes were finally filled with polymer while inner diameter of tubes became smaller, which can be proved by comparing the morphology of pure $\mathrm{TiO}_{2}$ NTs in Figure 2a with that of $\mathrm{PPy} / \mathrm{TiO}_{2} \mathrm{NTs}$ in Figure 2b. By contrast, in Fig. 2c, the surface of $\mathrm{PPy} / \mathrm{TiO}_{2} \mathrm{NTs}$ substrate with hollow structure for $\mathrm{S} / \mathrm{PPy} / \mathrm{TiO}_{2} \mathrm{NTs}-160$ sample is nearly covered by sulfur. However, as displayed in Fig. 2d, the morphology of S/PPy/TiO 2 NTs300 still presented a tube-like structure, but with thicker walls and corresponding smaller inner tube diameter of $\sim 80 \mathrm{~nm}$. The formation of this microstructure may be caused by the different heat treatment during the loading of sulfur into the substrates. As is known, elemental sulfur $\left(\mathrm{S}_{8}\right)$ has the lowest viscosity at $155^{\circ} \mathrm{C}$. When the temperature rose to $160{ }^{\circ} \mathrm{C}$, the elemental sulfur $\left(\mathrm{S}_{8}\right)$ became liquid and could infuse into the host structure. However, the agglomeration of sulfur particle was caused easily during the cooling process, resulting in the aggregation of superficial sulfur on the surface of the tubes as displayed in Fig. 2c. On the contrary, sulfur can be vaporized at elevated temperatures so that sulfur vapor could move into the tubes uniformly to the bottom of the tube. The 
EDS pattern (Fig. S2) shows the elemental composition of S/PPy/TiO 2 NTs-300 (heat treated at 300 ${ }^{\circ} \mathrm{C}$ ), which consists of element $\mathrm{C}$, element $\mathrm{S}$, element $\mathrm{O}$ and Ti. The large intensity of element $\mathrm{C}$ and element S proves the existence of PPy and sulfur.

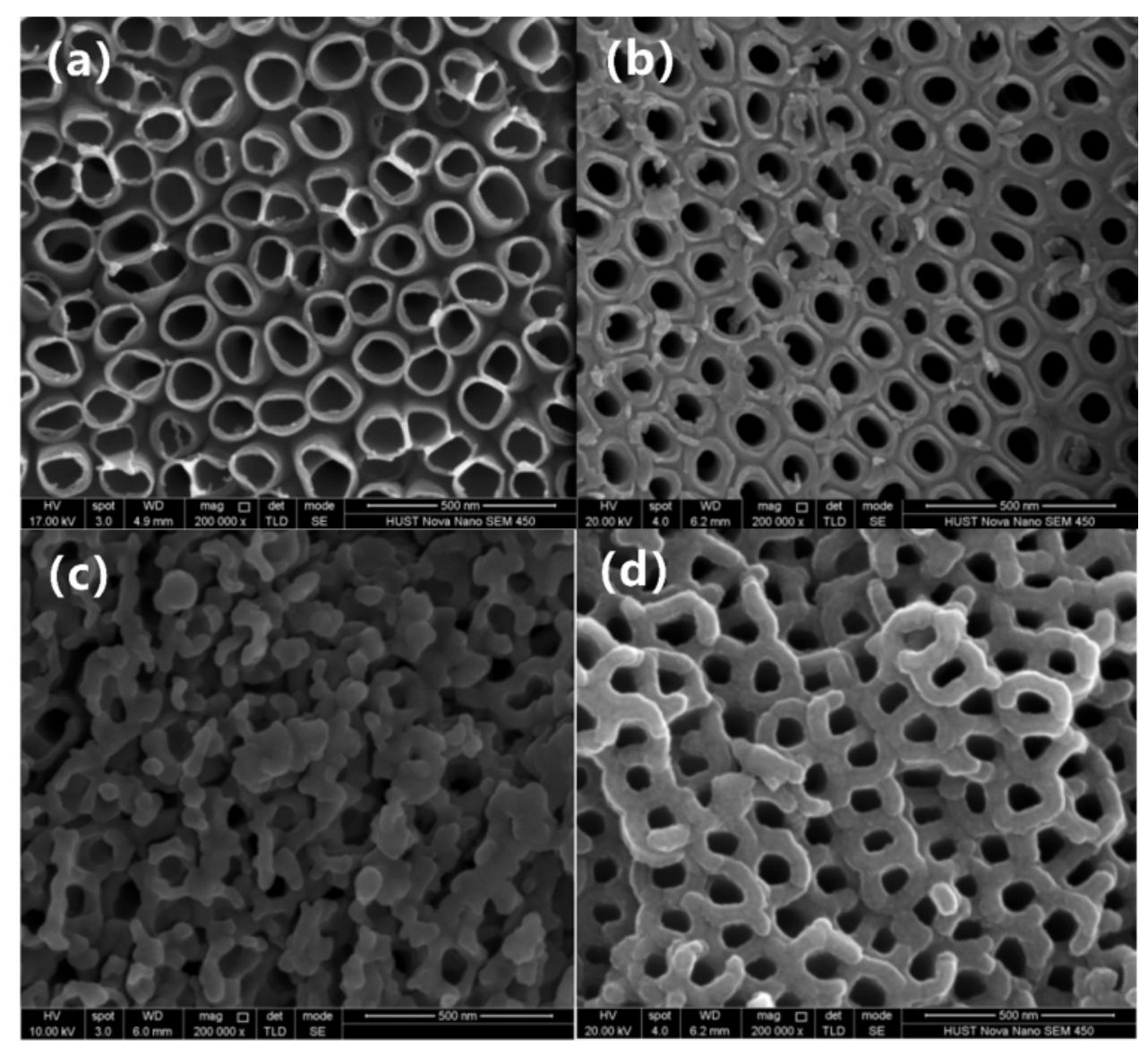

Fig. 2. FESEM images of top-surface of pure $\mathrm{TiO}_{2} \mathrm{NTs}(\mathrm{a}), \mathrm{PPy} / \mathrm{TiO}_{2} \mathrm{NTs}(\mathrm{b}), \mathrm{S} / \mathrm{PPy} / \mathrm{TiO}_{2} \mathrm{NTs}-160$ (c), and $\mathrm{S} / \mathrm{PPy} / \mathrm{TiO}_{2} \mathrm{NTs}-300$ (d).

The cross section photographs of samples are exhibited in Fig. 3. In comparison with the pure $\mathrm{TiO}_{2}$ NTs in Fig. 3a, a distinct polymer layer is observed along the nanotube walls in PPy/ $\mathrm{TiO}_{2}$ NTs sample. The FE-SEM image shown in Fig. $3 \mathrm{c}$ is a side view near the mouth of the nanotube for $\mathrm{S} / \mathrm{PPy} / \mathrm{TiO}_{2} \mathrm{NTs}-160$ sample. We can see that most of nanotubes are unfilled with sulfur near the mouth of the tube. Possibly, sulfur that located around the mouth of the tube is agglomerated from the nanotube and is aggregated on the surface of nanotubes film because of the lower temperature 
of heating process, which is coincident with the analysis in this reference[28]. Fig. 3d is the cross section photograph of $\mathrm{S} / \mathrm{PPy} / \mathrm{TiO}_{2} \mathrm{NTs}-300$. It is clear that sulfur is impregnated into the nanotubes and distributed across the tubes. The side-surface graphs that are taken near the bottom of the tubes show the deposits inside of the nanotubes (Fig. S3). We can speculate that the polymer membranes were deposited along the walls of the nanotubes (inside and outside) while the sulfur filled the inside of the tubes. It is noteworthy that tubes near the bottom show the smaller inner diameter of $\sim 50 \mathrm{~nm}$ (Fig. S3a, inset) and bigger external diameter of $\sim 140 \mathrm{~nm}$ (Fig. S3b) than that near the top. It makes sense since the metal $\mathrm{Ti}$ substrate has a greater conductivity than the $\mathrm{TiO}_{2}$ nanotube arrays, so the PPy deposition can slightly get faster near the bottom of tubes than near the top of tubes. The nonuniform thicknesses of deposits from top to bottom were further observed with TEM.

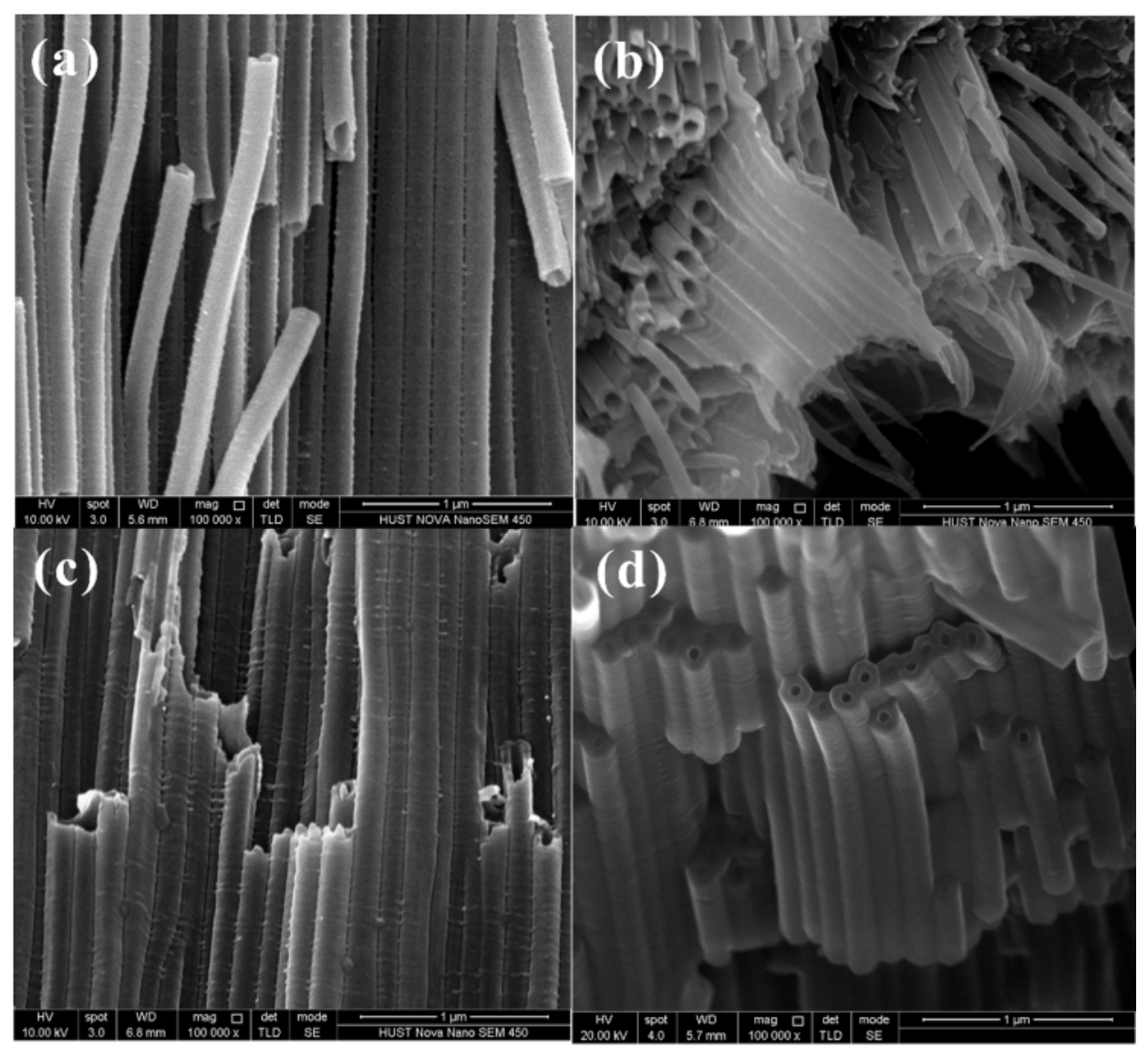

Fig. 3. FE-SEM images of cross-section of pure $\mathrm{TiO}_{2} \mathrm{NTs}(\mathrm{a}), \mathrm{PPy} / \mathrm{TiO}_{2} \mathrm{NTs}$ (b) $\mathrm{S} / \mathrm{PPy} / \mathrm{TiO}_{2} \mathrm{NTs}-160$ (c), and $\mathrm{S} / \mathrm{PPy} / \mathrm{TiO}_{2}$ NTs-300 (d) 
Fig.4 shows the TEM images of a single tube of the $\mathrm{S} / \mathrm{PPyTiO}_{2}$ NTs-300 sample in which the bottom of the single tube is exhibited in Fig. 4a. After magnification, a distinct structure of three layers is presented (Fig. 4b). A gray amorphous border is observed on the tube wall, which refers to PPy layers. Then, from a higher magnification to visualize the second layer (inset of Fig. 4b), the lattice fringe is apparent. The interplanar spacing is $0.35 \mathrm{~nm}$, corresponding to the (101) crystallographic plane of anatase, which is consistent with XRD of $\mathrm{TiO}_{2} \mathrm{NTs}$. Fig.4c and Fig.4d show the EDS line scanning along the cross direction and axis section of the top of the single tube, respectively. The EDS spectra prove the existence and distribution of sulfur in the tubes. Besides, the carbon content along cross section suggests the uniform distribution of PPy. The prepared other samples (pure $\mathrm{TiO}_{2} \mathrm{NTs}, \mathrm{PPy} / \mathrm{TiO}_{2} \mathrm{NTs}, \mathrm{S} / \mathrm{PPy} / \mathrm{TiO}_{2} \mathrm{NTs}-160$ ) also were characterized by transmission electron microscopy. Fig. S4a features a single $\mathrm{TiO}_{2}$ nanotube which reveals the nanotube structure and the smooth wall with a thickness of about $10 \mathrm{~nm}$ (inset). Fig. S4b shows the TEM image of nanotubes after PPy was polymerized. The thickening of tube wall $(\sim 30 \mathrm{~nm})$ suggests that PPy was uniformly grown on the inner and outer wall of the $\mathrm{TiO}_{2}$ nanotube. The TEM image of S/PPyTiO 2 NTs-160 sample is exhibited in Fig. S4c. From the higher magnification to visualize the inside (inset of Fig. S4c), agglomeration of nanoparticles can be observed, which is consistent with the SEM results.

The phases of the composite were characterized by XRD with the testing range from $20^{\circ}$ to $70^{\circ}$ (see Fig. S5). To reveal the characteristic of PPy, PPy was individually prepared by electrochemical deposition on a Ti metal plate using a constant current density of $1.0 \mathrm{~mA} \mathrm{~cm}^{-2}$. As shown in Fig. S5a, PPy shows a broad, weak diffraction centered at around $25^{\circ}$, which corresponds to the amorphous bulge appearing around $25^{\circ}$ in $\mathrm{S} / \mathrm{PPy} / \mathrm{TiO}_{2} \mathrm{NTs}-160$ and $\mathrm{S} / \mathrm{PPy} / \mathrm{TiO}_{2} \mathrm{NTs}-300$ in Fig. 
S5b. Sulfur exhibits a high diffraction peak at $23.4^{\circ}$ and $27.8^{\circ}$, corresponding to the crystal plane of (222) and (040)[20, 29]. The phase of $\mathrm{TiO}_{2}$ NTs is typical anatase[30], which is consistent with TEM analysis. All of $\mathrm{S} / \mathrm{TiO}_{2} \mathrm{NTs}, \mathrm{S} / \mathrm{PPy} / \mathrm{TiO}_{2} \mathrm{NTs}-160$ and $\mathrm{S} / \mathrm{PPy} / \mathrm{TiO}_{2}$ NTs-300 show several diffraction peaks of sulfur, which shows the existence of sulfur in the arrays.

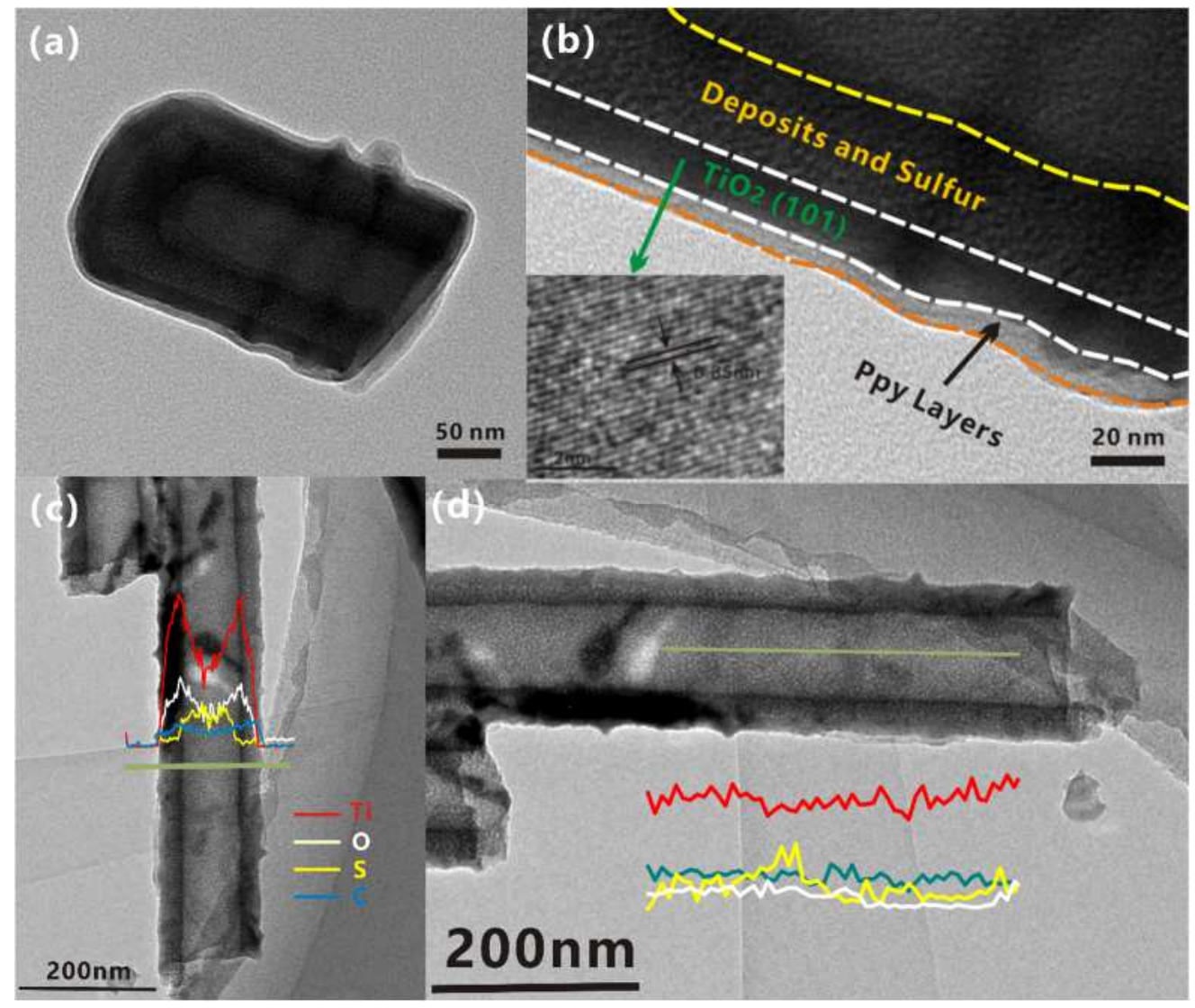

Fig. 4 TEM image of bottom of tube (a) and distinct layers after magnification (b) (inset: the lattice fringe of the second layer) and EDS line scanning of S/PpyTiO 2 NTs-300. (c) The EDS line scanning along the cross section of the tube. (d) The EDS line scanning along the axis of the tube. Titanium signal is red, oxygen signal is white, carbon signal is blue and sulfur signal is yellow.

Thermogravimetric analysis (TG) was carried out to determine the content of sulfur in the asprepared cathode materials. Fig. 5 shows the TG curves of several cathodes ranging from $38{ }^{\circ} \mathrm{C}$ to $500{ }^{\circ} \mathrm{C}$ under a $\mathrm{N}_{2}$ atmosphere. The curve of $\mathrm{S} / \mathrm{TiO}_{2}$ NTs shows no significant change until the 
temperature reached $180{ }^{\circ} \mathrm{C}$. After that, the mass of $\mathrm{S} / \mathrm{TiO}_{2} \mathrm{NTs}$ decreased gradually until the temperature reached $300{ }^{\circ} \mathrm{C}$. The mass loss of $\mathrm{S} / \mathrm{TiO}_{2} \mathrm{NTs}$ exhibits a similar change of mass rate compared to that of elemental sulfur, which indicates that the mass loss of $\mathrm{S} / \mathrm{TiO}_{2} \mathrm{NTs}$ originated from the evaporation of sulfur. Since $\mathrm{TiO}_{2}$, a stable metal oxide, shows no mass change during the test range, the sulfur content in $\mathrm{S} / \mathrm{TiO}_{2} \mathrm{NTs}$ was determined as $61.93 \%$. In comparison with $\mathrm{S} / \mathrm{TiO}_{2}$ NTs, S/PPy/TiO 2 NTs cathodes show different change of mass. They both have almost no changes until the temperature reached $250{ }^{\circ} \mathrm{C}$ and the mass keeps decreasing until the turning point that occurs at a higher temperature about $350^{\circ} \mathrm{C}$. It is a great possibility that the evaporation of sulfur is hindered by the PPy coating that could be attributed to the formation of C-S bonds between PPy and sulfur in the composites. In addition, the curve of $\mathrm{S} / \mathrm{PPy} / \mathrm{TiO}_{2}$ NTs-300 shows a little inclination after the turning point. This phenomenon might be related to the change in the molecular structure of the sulfur caused by the elevated temperature, which will be discussed in the following analysis of electrochemical properties. In Fig. 5, mass losses of S/PPy/TiO 2 NTs-160 and S/PPy/TiO 2 NTs300 are $71.67 \%$ and $66.2 \%$ at the turning point, suggesting that the sulfur contents in $\mathrm{S} / \mathrm{PPy} / \mathrm{TiO}_{2}$ NTs-160 and S/PPy/TiO 2 NTs-300 are $70.4 \%$ and $64.68 \%$, respectively. 


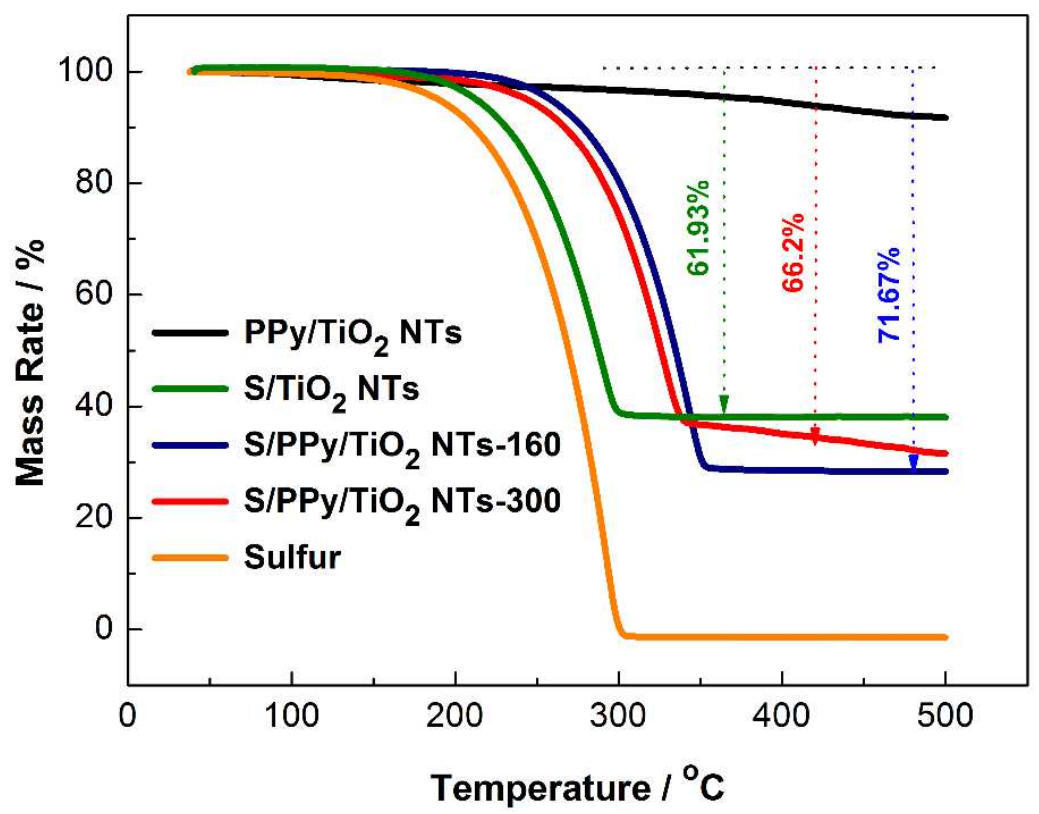

Fig. 5. TGA curve of sulfur, $\mathrm{PPy} / \mathrm{TiO}_{2} \mathrm{NTs}, \mathrm{S} / \mathrm{TiO}_{2} \mathrm{NTs}, \mathrm{S} / \mathrm{PPy} / \mathrm{TiO}_{2} \mathrm{NTs}-160$ and $\mathrm{S} / \mathrm{PPy} / \mathrm{TiO}_{2} \mathrm{NTs}-300$

To further determine the presence of PPy and the existence of C-S chemical bonds in the $\mathrm{S} / \mathrm{PPy} / \mathrm{TiO}_{2} \mathrm{NT}$ composites, fourier transform infrared spectroscopy spectra was used. Fig. 6(a) shows FT-IR spectra of pure $\mathrm{TiO}_{2} \mathrm{NTs}, \mathrm{PPy} / \mathrm{TiO}_{2} \mathrm{NTs}$, S/PPy/TiO 2 NTs-160 and S/PPy/TiO 2 NTs300 obtained in the wave-number range from 500 to $2100 \mathrm{~cm}^{-1}$. The FT-IR spectra of pure $\mathrm{TiO}_{2}$ NTs shows no obvious vibrational activity within the range tested, while $\mathrm{PPy} / \mathrm{TiO}_{2} \mathrm{NTs}$ shows the spectral characteristics of polypyrrole as reported in references. The bands at $1584 \mathrm{~cm}^{-1}$ and 1477 $\mathrm{cm}^{-1}$ correspond to the fundamental vibration of the conjugated double bonds $\mathrm{C}=\mathrm{C}$ stretching vibration of pyrrole rings. The peaks at $1313 \mathrm{~cm}^{-1}$ and $1119 \mathrm{~cm}^{-1}$ correspond to $\mathrm{C}-\mathrm{N}$ stretching vibrations of the benzoid and quinoid rings[31]. The sharp peak in the vicinity of $1040 \mathrm{~cm}^{-1}$ could be assigned to the $\mathrm{C}-\mathrm{H}$ deformation vibration of pyrrole rings[32]. However, the spectra of S/PPy/TiO 2 NTs-160 and S/PPy/TiO 2 NTs-300 are slightly different from that of $\mathrm{PPy} / \mathrm{TiO}_{2} \mathrm{NTs}$. Two new bands appear around 674 and $928 \mathrm{~cm}^{-1}$. The peak at $674 \mathrm{~cm}^{-1}$ can be assigned to C-S stretching[33]. There are some reports attributing the peak at 928 and $943 \mathrm{~cm}^{-1}$ to the aromatic ring containing C-S bond[34, 35]. Since Element sulfur shows no vibrational activity in the 900 to 2000 
$\mathrm{cm}^{-1}$ range, we assign the band at $928 \mathrm{~cm}^{-1}$ to the breath of pyrrole aromatic ring containing $\mathrm{C}-\mathrm{S}$ bonds. Besides, in comparison with $\mathrm{PPy} / \mathrm{TiO}_{2} \mathrm{NTs}$, the intensity of the C-H vibration band at 1040 $\mathrm{cm}^{-1}$ in the $\mathrm{S} / \mathrm{PPy} / \mathrm{TiO}_{2} \mathrm{NT}$ composites is significantly weakened, suggesting the substitution of $\mathrm{S}$ atoms for $\mathrm{H}$ atoms on the pyrrole ring, which further confirms the formation of $\mathrm{C}-\mathrm{S}$ bonds.

The formation of C-S bonds can also be observed through Raman characterization. Fig. 6(b) shows Raman spectra of sulfur, pure PPy, $\mathrm{PPy}_{\mathrm{TTO}} \mathrm{NTs}_{2}$, S/PPy/TiO ${ }_{2}$ NTs-160 and S/PPy/TiO ${ }_{2} \mathrm{NTs}^{-}$ 300 in range of $100-2000 \mathrm{~cm}^{-1}$. In Fig. 6(b), $\mathrm{PPy} / \mathrm{TiO}_{2} \mathrm{NTs}$ displays the strongest Raman band of $\mathrm{TiO}_{2}$ NTs at $142.1 \mathrm{~cm}^{-1}$ while showing the typical PPy peaks between 800 and $1800 \mathrm{~cm}^{-1}$, which match up with the Raman spectrum of pure PPy. The most significant band obtained around 1580 $\mathrm{cm}^{-1}$ corresponds to the backbone stretching mode of $\mathrm{C}=\mathrm{C}$ bonds of pyrrole rings[36]. The peak in the vicinity of $1380 \mathrm{~cm}^{-1}$ is attributed to the ring-stretching mode of PPy. The band at around 1080 $\mathrm{cm}^{-1}$ is assigned to $\mathrm{C}-\mathrm{H}$ in-plane deformation[37]. The double peaks at about $990 \mathrm{~cm}^{-1}$ and $940 \mathrm{~cm}^{-}$ ${ }^{1}$ are respectively assigned to the ring deformation associated with radical cation (polaron) and dication (bipolaron)[38]. S/PPy/TiO 2 NTs-160 and $\mathrm{S} / \mathrm{PPy} / \mathrm{TiO}_{2}$ NTs-300 still show the three main peaks of elemental sulfur but with very low intensity, which means sulfur is well confined in the nanotube arrays. Compared with the spectra of $\mathrm{PPy} / \mathrm{TiO}_{2}$ NTs between 800 and $1800 \mathrm{~cm}^{-1}$, $\mathrm{S} / \mathrm{PPy} / \mathrm{TiO}_{2} \mathrm{NTs}-160$ and $\mathrm{S} / \mathrm{PPy}_{\mathrm{TiO}} \mathrm{T}_{2} \mathrm{NTs}-300$ show a series of changes. First of all, the band at $1080 \mathrm{~cm}^{-1}$ assigned to C-H in-plane deformation disappears, which is consistent with FT-IR. The replacement of $\mathrm{H}$ atoms on the pyrrole ring by $\mathrm{S}$ atoms leads to the absence of the band at $1080 \mathrm{~cm}^{-}$ 1. Secondly, the double peaks at about $990 \mathrm{~cm}^{-1}$ and $940 \mathrm{~cm}^{-1}$ also vanish from the spectra. As mentioned before, these two peaks are attributed to the ring deformation associated with polaron and bipolaron of PPy. It is known that the charge carrier of conductive polymers is not the traditional 
electrons or holes but are composite particles called soliton, antisoliton, polaron or bipolaron. The existence of polaron or bipolaron is related to the motion and configuration of electrons. The disappearance of the double peaks suggested that the formation of C-S bonds could take effect on the status of electrons around PPy. It is also reflected in the fact that the formation of C-S bonds has an influence on the density distribution of the electron cloud of PPy and changes in the bond length and energy of pyrrole rings, which lead to the shift of the bands at around $1580 \mathrm{~cm}^{-1}$ and $1380 \mathrm{~cm}^{-1}$ to $1550 \mathrm{~cm}^{-1}$ and $1350 \mathrm{~cm}^{-1}$, respectively.
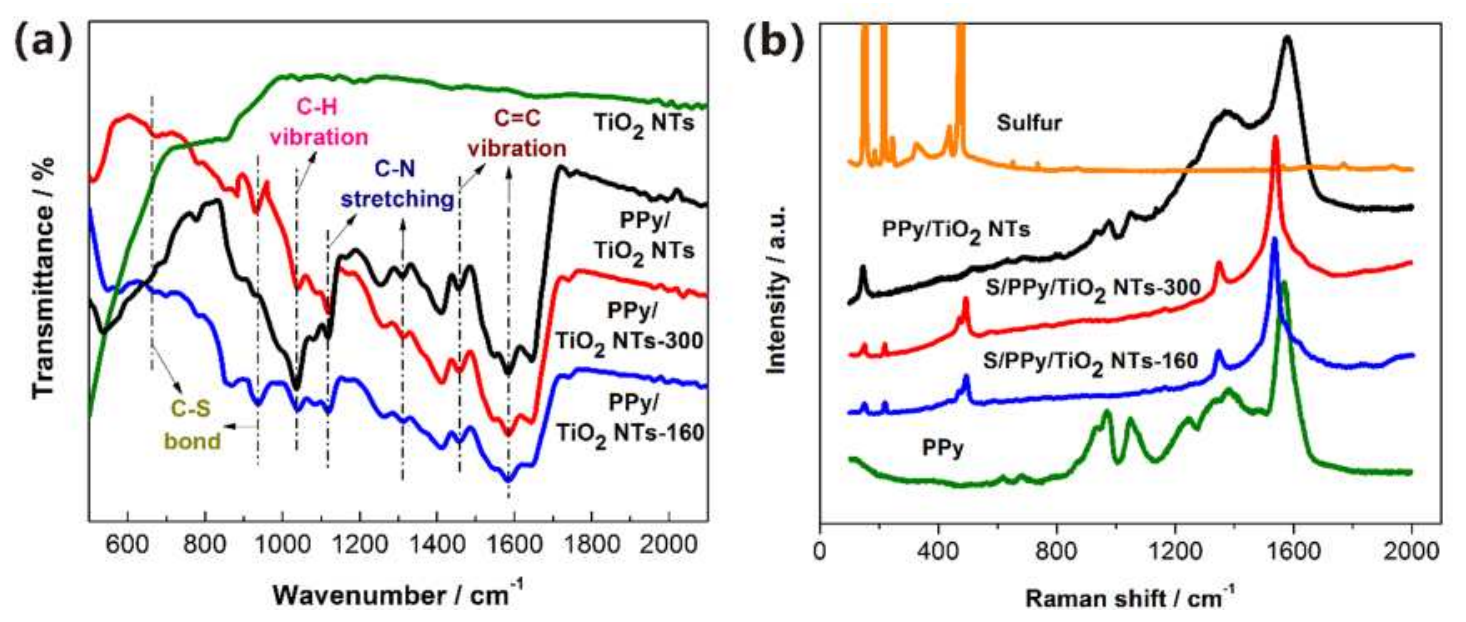

Fig. 6. (a) FT-IR spectra of pure $\mathrm{TiO}_{2} \mathrm{NTs}, \mathrm{PPy} / \mathrm{TiO}_{2} \mathrm{NTs}, \mathrm{S} / \mathrm{PPy} / \mathrm{TiO}_{2} \mathrm{NTs}-160$ and $\mathrm{S} / \mathrm{PPy} / \mathrm{TiO}{ }_{2} \mathrm{NTs}-300$. (b) Raman spectra of sulfur, pure PPy, $\mathrm{PPy} / \mathrm{TiO}_{2}$ NTs, S/PPy/TiO 2 NTs-160 and S/PPy/TiO 2 NTs-300

To investigate the electrochemical reaction mechanism of $\mathrm{S} / \mathrm{TiO}_{2} \mathrm{NTs}$ and $\mathrm{S} / \mathrm{PPy} / \mathrm{TiO}_{2} \mathrm{NTs}$ cathode, cyclic voltammetry (CV) was performed between 3.0 and $1.8 \mathrm{~V}$ using a scan rate of 0.1 $\mathrm{mV} \mathrm{s}^{-1}$. Generally, the voltage range of electrochemical testing on lithium sulfur cells is between 3.0 and $1.5 \mathrm{~V}$. However, in our case, $\mathrm{TiO}_{2} \mathrm{NTs}$ is in itself an active substance and has a reduction reaction peak and a discharge plateau around $1.7 \mathrm{~V}$ (as displayed in Fig. S6). Because of the integrity of the electrode structure in which the $\mathrm{TiO}_{2} \mathrm{NTs}$ and the underlying metal substrate are addressed as a 
whole, it is difficult to measure the mass of $\mathrm{TiO}_{2} \mathrm{NTs}$ without destroying the electrode if it is going to be considered as part of the active substance. Therefore, we conducted all electrochemical testing in the range between 3.0 and $1.8 \mathrm{~V}$ to limit the capacity of the cells to that of sulfur. Fig. 7a shows the $\mathrm{CV}$ curves of the second cycles of three cathode materials. Two main reduction peaks around $2.35 \mathrm{~V}$ and $2.08 \mathrm{~V}$ are observed during the cathodic scan of $\mathrm{S} / \mathrm{TiO}_{2} \mathrm{NTs}$, suggesting a typical twostep reduction reaction of sulfur: The peak at about $2.35 \mathrm{~V}$ is related to sulfur reduction to lithium polysulfides $\mathrm{Li}_{2} \mathrm{~S}_{\mathrm{n}}(4 \leqslant \mathrm{n} \leqslant 8)$. Then these long chain polysulphides are further reduced to $\mathrm{LiS}_{2}$ or $\mathrm{Li}_{2} \mathrm{~S}_{2}$ at lower voltage of $2.08 \mathrm{~V}$. In the following anodic scan, only one broad peak at about 2.5 $\mathrm{V}$ is observed. It has been reported that this envelope curve is an overlap of two expected oxidation peaks caused by the high overvoltage between $\mathrm{Li}_{2} \mathrm{~S}$ and Li polysulfides[39]. The CV curve of $\mathrm{S} / \mathrm{PPy} / \mathrm{TiO}_{2} \mathrm{NTs}-160$ also shows two main reduction peaks but has a little different behaviour. In comparison with $\mathrm{S} / \mathrm{TiO}_{2} \mathrm{NTs}$, the magnitude of the peak around $2.08 \mathrm{~V}$ increased and another peak had a negative shift from $2.35 \mathrm{~V}$ to $2.2 \mathrm{~V}$ in S/PPy/TiO 2 NTs- 160 . The reason could be also attributed to the formation of C-S bond as a result of the interaction between PPy and S, which suppressed the reaction route of $\mathrm{S}_{8} \rightarrow \mathrm{S}_{6}{ }^{2-} \rightarrow \mathrm{S}_{4}{ }^{2-}$. More interestingly, The $\mathrm{CV}$ curve of $\mathrm{S} / \mathrm{PPy} / \mathrm{TiO}_{2}$ NTs-300 only showed one broad peak at the voltage of 2.1-2.2 V. We attribute this to the change in the molecular structure of sulfur with the increasing temperature. It has been reported that sulfur vapor is in the form of $\mathrm{S}_{8}(76.5 \%)$ and $\mathrm{S}_{6}(23.5 \%)$ at $200{ }^{\circ} \mathrm{C}[40]$. At $300{ }^{\circ} \mathrm{C}$, it possesses a significant fraction of $\mathrm{S}_{6}(58.8 \%)$ and $\mathrm{S}_{2}(16.4 \%)$ molecules, which are more reactive since they possess a greater fraction of sulfur terminal atom. It stands a good chance that sulfur mainly exists as $\mathrm{S}_{8}$ in $\mathrm{S} / \mathrm{PPy} / \mathrm{TiO}_{2} \mathrm{NTs}^{-}$ 160 but as $\mathrm{S}_{6}$ and $\mathrm{S}_{2}$ in $\mathrm{S} / \mathrm{PPy} / \mathrm{TiO}_{2} \mathrm{NTs}-300$. The small size of $\mathrm{S}_{6}(6.9 \AA)$ and $\mathrm{S}_{2}(5.2 \AA)$ can easily defuse into the fluffy structure of polypyrrole and their high reactivity make the formation of C-S 
bond easier[18]. These reasons lead to the further suppression of reaction route of $\mathrm{S}_{8} \rightarrow \mathrm{S}_{6}{ }^{2-} \rightarrow \mathrm{S}_{4}{ }^{2-}$ in $\mathrm{S} / \mathrm{PPy} / \mathrm{TiO}_{2}$ NTs-300 and make the two main reduction peaks for sulfur less distinguishable.

Fig. $7 \mathrm{~b}$ shows the second charge/discharge curves of three cathode materials at current rate of $0.05 \mathrm{C}\left(1 \mathrm{C}=1675 \mathrm{~mA} \mathrm{~g}^{-1}\right)$. The discharge curve of $\mathrm{S} / \mathrm{TiO}_{2}$ NTs exhibited two obvious potential plateaus. The first plateau around $2.4 \mathrm{~V}$ corresponds to the first reduction peak at about $2.35 \mathrm{~V}$ of $\mathrm{S} / \mathrm{TiO}_{2} \mathrm{NTs}$ in Fig. $7 \mathrm{a}$, and the second plateau at around $2.1 \mathrm{~V}$ corresponds to the second reduction peak at $2.08 \mathrm{~V}$. In contrast, the first plateau of $\mathrm{S} / \mathrm{PPy} / \mathrm{TiO}_{2} \mathrm{NTs}-160$ is less dramatic and its second plateau at around $2.1 \mathrm{~V}$ shows relatively stable span, which is related to the reduction of sulfur species with C-S bonds and is consistent with our analysis on CV curve. It is noteworthy that the first plateau of $\mathrm{S} / \mathrm{PPy} / \mathrm{TiO}_{2} \mathrm{NTs}-300$ is obviously suppressed and changed to a slope-shape curve. The reason should be attributed to the much stronger bond between polypyrrole and sulfur with the increasing temperature, which is consistent with the cyclic voltammetry characterization as detailed in the above paragraph. Also from Fig. $7 \mathrm{~b}$, it can be noticed that the $\mathrm{S} / \mathrm{PPy}_{\mathrm{TiO}}-300$ cathode had a higher capacity than the other two at the second cycle. It has been reported that the long sulfur chains $\left(-S_{x^{-}}, x>4\right)$ bonded on carbon can lead to high capacities[28, 41]. As mentioned in the previous section, $\mathrm{S} / \mathrm{PPy} / \mathrm{TiO}_{2} \mathrm{NTs}-300$ cathode is in the form of $\mathrm{S}_{8}(24.8 \%), \mathrm{S}_{6}(58.8 \%)$ and $\mathrm{S}_{2}(16.4 \%)$ at $300{ }^{\circ} \mathrm{C}$. So it still shows $83.6 \%$ of long sulfur chains, which lead to the high capacity of the cathode. In addition, the C-S bonds and the special hollow coaxial heterogeneous structure all can allow sulfur to fully take part in the chemical reaction and as a result to output high capacity. So the performance improvement in $\mathrm{S} / \mathrm{PPy} / \mathrm{TiO}_{2}-300$ sample should be a result of combining multi-factors. However, the $\mathrm{S} / \mathrm{PPy} / \mathrm{TiO}_{2}-160$ sample has more long sulfur chains that should show higher capacity than the $\mathrm{S} / \mathrm{PPy} / \mathrm{TiO}_{2}-300$ sample. Fig. $\mathrm{S} 7$ features the discharge curves of the first cycle for three 
cathodes compared with the performance of second cycle at $0.05 \mathrm{C}$. Indeed, the $\mathrm{S} / \mathrm{PPy} / \mathrm{TiO}_{2}-160$ cathode exhibited highest capacity in the first cycle among the three cathodes. This confirms the coincidence with the reference once again[41]. Since the $\mathrm{S} / \mathrm{PPy} / \mathrm{TiO}_{2}-160$ sample has more long sulfur chains than the $\mathrm{S} / \mathrm{PPy} / \mathrm{TiO}_{2}-300$ sample, it shows higher capacity but inferior cycling stability.

The discharge capacity and coulombic efficiency of $\mathrm{S} / \mathrm{TiO}_{2} \mathrm{NTs}$ and $\mathrm{S} / \mathrm{PPy} / \mathrm{TiO}_{2} \mathrm{NTs}_{\text {cathode at }}$ a rate of $0.1 \mathrm{C}$ is shown in Fig. $7 \mathrm{c}$. The $\mathrm{S} / \mathrm{TiO}_{2} \mathrm{NTs}$ cathode shows the fastest capacity fading of $37.3 \%$ retention after 100 cycles. There was a large capacity drop at the first and the second cycle. This may result from the dissolution of superficial sulfur covered on the top surface or attached to the wall of $\mathrm{TiO}_{2}$ NTs. The resultant polysulfide produced by the superficial sulfur during discharge process cannot be confined into the high ordered arrays due to the absence of S-C bonds and dissolved into electrolyte quickly, which led to the loss of active mass of sulfur. However, the $\mathrm{S} / \mathrm{PPy} / \mathrm{TiO}_{2} \mathrm{NTs}-160$ cathode shows an improved stability with $58.2 \%$ retention after 100 cycles. The initial attenuation of capacity in the first 20 cycles should be attributed to the dissolution of superficial sulfur covered on the top surface of $\mathrm{TiO}_{2}$ NTs. After 20 cycles, the better stability indicates that the appropriate structure of highly ordered $\mathrm{TiO}_{2} \mathrm{NTs}$ arrays have a positive effect on the capacity performance of the cathode. The high coulombic efficiency of about $95 \%$ also showed the advantage of $\mathrm{TiO}_{2}$ as a supporting material for the sulfur electrode. In addition, an interesting phenomenon should be mentioned. The discharge capacity of $\mathrm{S} / \mathrm{PPy} / \mathrm{TiO}_{2}-300$ in the second cycle is smaller than that for $\mathrm{S} / \mathrm{PPy} / \mathrm{TiO}_{2}-160$ in Fig. 7c, which is different with the result in Fig. 7b. The difference should be attributed to the different C-rates in which we use the current density of 0.05 $\mathrm{C}$ to feature the voltage curves of discharge/charge in Fig. 7b, while use the higher current density of $0.1 \mathrm{C}$ to reflect the cycle stability of the electrodes. We believe the lower current density lead to 
longer discharge process for cathode materials to contact with the electrolyte sufficiently. So the lower current density can show the real mechanism in an equilibrium state. At the lower current density, the $\mathrm{S} / \mathrm{PPy} / \mathrm{TiO}_{2}-160$ sample has the sufficient time to release elemental sulfur and form soluble polysulfides during cell operations, resulting in a fast capacity fading in the $2^{\text {nd }}$ cycle. At the higher current density, a relative slow fading can be supposed due to the non-equilibrium state. Therefore, the discharge capacity of $\mathrm{S} / \mathrm{PPy} / \mathrm{TiO}_{2}-160$ in the second cycle is still higher than that of $\mathrm{S} / \mathrm{PPy} \mathrm{TiO}_{2}-300$ at $0.1 \mathrm{C}$. However, as shown in Fig. 7c, after 4 cycles, the discharge capacity of $\mathrm{S} / \mathrm{PPy} / \mathrm{TiO}_{2}-160$ become smaller compared with that of $\mathrm{S} / \mathrm{PPy} / \mathrm{TiO}_{2}-300$ cathode. In contrast, the S/PPy/TiO 2 NTs-300 has the best performance among all three cathodes with a stable capacity of $1150 \mathrm{mAh} \mathrm{g}^{-1}$ after 100 cycles. This indicated that the heat treatment temperature had a profound influence on the capability of the $\mathrm{S} / \mathrm{PPy} / \mathrm{TiO}_{2} \mathrm{NT}$ cathode. When the heat treatment temperature was $160{ }^{\circ} \mathrm{C}$, sulfur mainly exists as $\mathrm{S}_{8}$ and has a few chemical bonds with polypyrrole. When the temperature was elevated to $300{ }^{\circ} \mathrm{C}$, the molecular structure of sulfur consisted largely of $\mathrm{S}_{6}$ and $\mathrm{S}_{2}$, which have more extensive chemical bonds with polypyrrole. Moreover, the higher temperature of $300{ }^{\circ} \mathrm{C}$ can remove the superficial sulfur, while allowing sulfur inside the arrays to diffuse as vapor into the tube deeply, even into the fluffy structure of the polypyrrole layers deposited on the tube wall, leading to a hollow coaxial heterogeneous structure in which sulfur has been uniformly distributed as shown by FESEM and TEM characterization. What is interesting and noteworthy is that the capacity after 100 cycles $\left(1150 \mathrm{mAh} \mathrm{g}^{-1}\right)$ in the $\mathrm{S} / \mathrm{PPy} / \mathrm{TiO}_{2}$ NTs-300 sample was even higher than that of the first cycle $\left(997 \mathrm{mAh} \mathrm{g}^{-1}\right)$ at $0.1 \mathrm{C}$. It seems that the cathode shows a fluctuation tendency in discharge capacities during cycles, which can be observed clearly in Fig. 7d. We attribute this fluctuation to the catalytic action of PS. It has been reported that PS has a catalytic 
action to help the redox reaction occur between sulfur and lithium sulfide [42]. Since the nanotube arrays and elastic PPy layers can trap the dissolved PS, we speculate that the detained PS inside the tube involved into redox reaction again when it reached a certain amount, leading to the increasing in capacity. And then the capacity slightly decreases in the wake of the slow dissolution of PS. The repetition of this process resulted in the fluctuation tendency in discharge capacity. Table S1 gave a summary about the performance of many advanced Li-S battery systems that have been designed revolving around $\mathrm{TiO}_{2}$ and $\mathrm{PPy}$ as the cathode materials. Although these recently reported corresponding materials have shown remarkable progress in terms of lithium storage performance, however, all of them show a trend of capacity degradation in the subsequent charge/discharge cycles. Only our present material exhibits an increasing tendency in capacity, suggesting that a unique structure and the resulting significant advantage have been formed in our electrode systems.

(a)

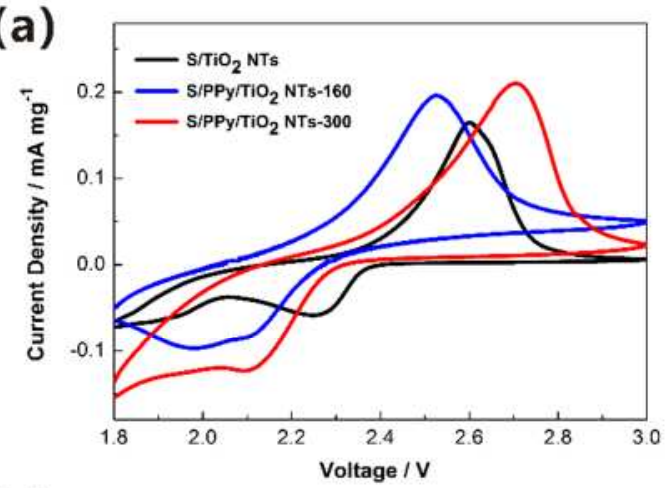

(c)

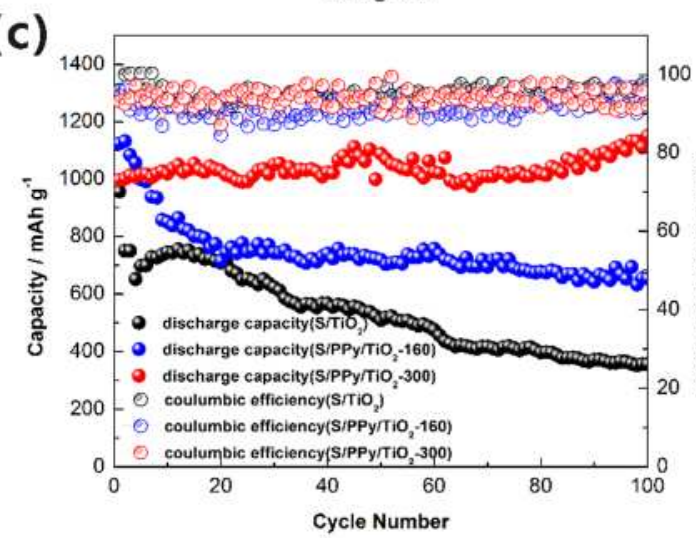

(b)

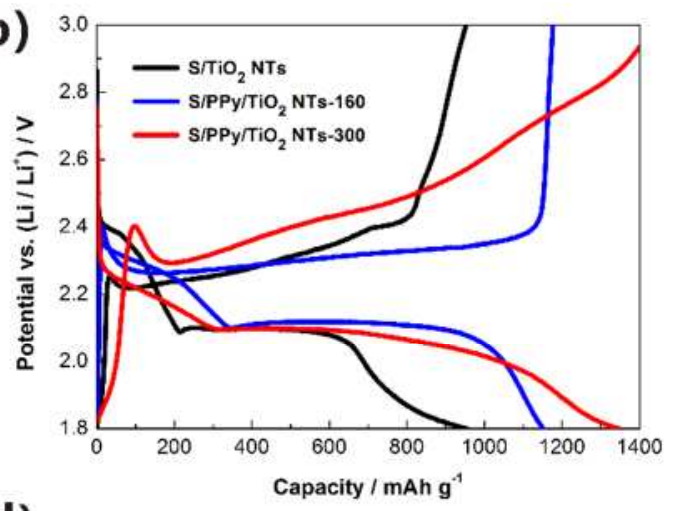

(d)

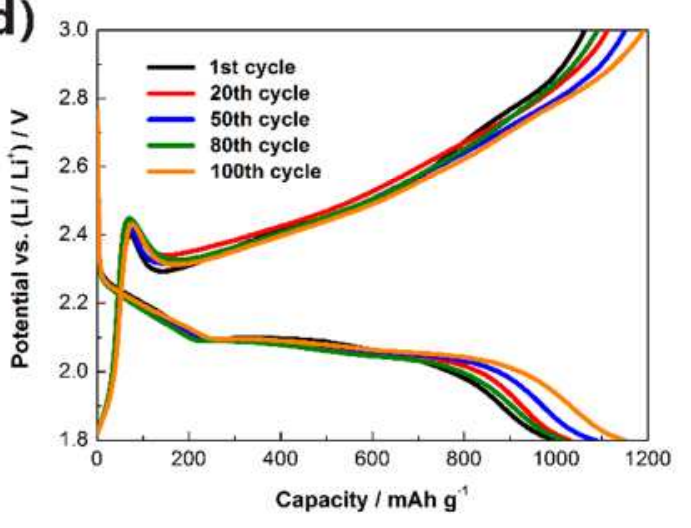

Fig. 7. Electrochemical performance of $\mathrm{S} / \mathrm{TiO}_{2} \mathrm{NTs}, \mathrm{S} / \mathrm{PPy} / \mathrm{TiO}_{2} \mathrm{NTs}-160$ and $\mathrm{S} / \mathrm{PPy} / \mathrm{TiO}_{2} \mathrm{NTs}-300$. (a) Cyclic 
voltammetry curves of the second cycles at scan rate of $0.1 \mathrm{mV} \mathrm{s}^{-1}$. (b) Discharge/charge curves of the second cycles at 0.05 C. (c) Cycling stability and Coulombic efficiencies over 100 cycles at 0.1 C. (d) Typical discharge/charge curves at the $1^{\text {st }}, 20^{\text {th }}, 50^{\text {th }}, 80^{\text {th }}$ and $100^{\text {th }}$ cycle for $\mathrm{S} / \mathrm{PPy} / \mathrm{TiO}_{2} \mathrm{NTs}-300$ at a current density of $0.1 \mathrm{C}$

For the resultant hollow coaxial heterogeneous structure, sulfur would be confined inside this nanotube substrate during the charge/discharge process and the strong C-S bond occurred on the tube wall can trap the soluble lithium polysulfides to reduce the loss of sulfur and alleviate the shuttle effect. This hollow coaxial heterogeneous structure can also provide void space to accommodate the large volume expansion of sulfur during lithiation coupled with polysulfide dissolution. Moreover, such a hollow structure allows more electrolyte into the inside of the nanotube and increases the contact interface between electrolyte and the active substance to a large extent, and as a result makes available a larger number of active reaction sites for sulfur to access a large number of Li ions and chemical reactions to occur. This point is clearly demonstrated in SEM images of the S/PPy/TiO 2 NTs-300 cathode before and after $100^{\text {th }}$ cycling. As is seen in Fig. 8 , the cycled electrode of $\mathrm{S} / \mathrm{PPy} / \mathrm{TiO}_{2}$ NTs-300 still maintains hollow tube-like structure with insoluble products covered on the tube walls. Whereas $\mathrm{S} / \mathrm{PPy} / \mathrm{TiO}_{2} \mathrm{NTs}-160$ cathode shows precipitation of insoluble products on the surface of nanotube arrays after $100^{\text {th }}$ cycling. So even the S/PPy/TiO 2 NTs-160 showed larger capacity in the first several cycles, but the capacity is strongly attenuated in the subsequent discharge/charge process until 20 cycles. On the contrary, the S/PPy/TiO 2 NTs-300 that has the hollow structure presented the best cycle stability with a high coulombic efficiency of about $96 \%$ among the three cathodes. This phenomenon is also reflected in their cyclic voltammogram characteristics as shown in Fig. S8. Fig. S9 is the discharge/charge capacity of 
$\mathrm{S} / \mathrm{PPy} / \mathrm{TiO}_{2} \mathrm{NTs}-300$ cycled at various $\mathrm{C}$-rates from $0.05 \mathrm{C}$ to $1 \mathrm{C}$. After an initial discharge capacity of $1314.9 \mathrm{mAh} \mathrm{g}^{-1}$ at $0.05 \mathrm{C}$, the discharge capacity began to stabilize at about $1350 \mathrm{mAh} \mathrm{g}^{-1}$. Further cycling at 0.1, 0.2, 0.5 and $1 \mathrm{C}$ showed high reversible capacities of 1130, 950, 760 and $500 \mathrm{mAh}$ $\mathrm{g}^{-1}$, respectively. When the C-rate was switched abruptly from 1 to $0.05 \mathrm{C}$ again, a high capacity near $1150 \mathrm{mAh} \mathrm{g}^{-1}$ was still obtained, indicating the excellent high rate capability of the cathode material.

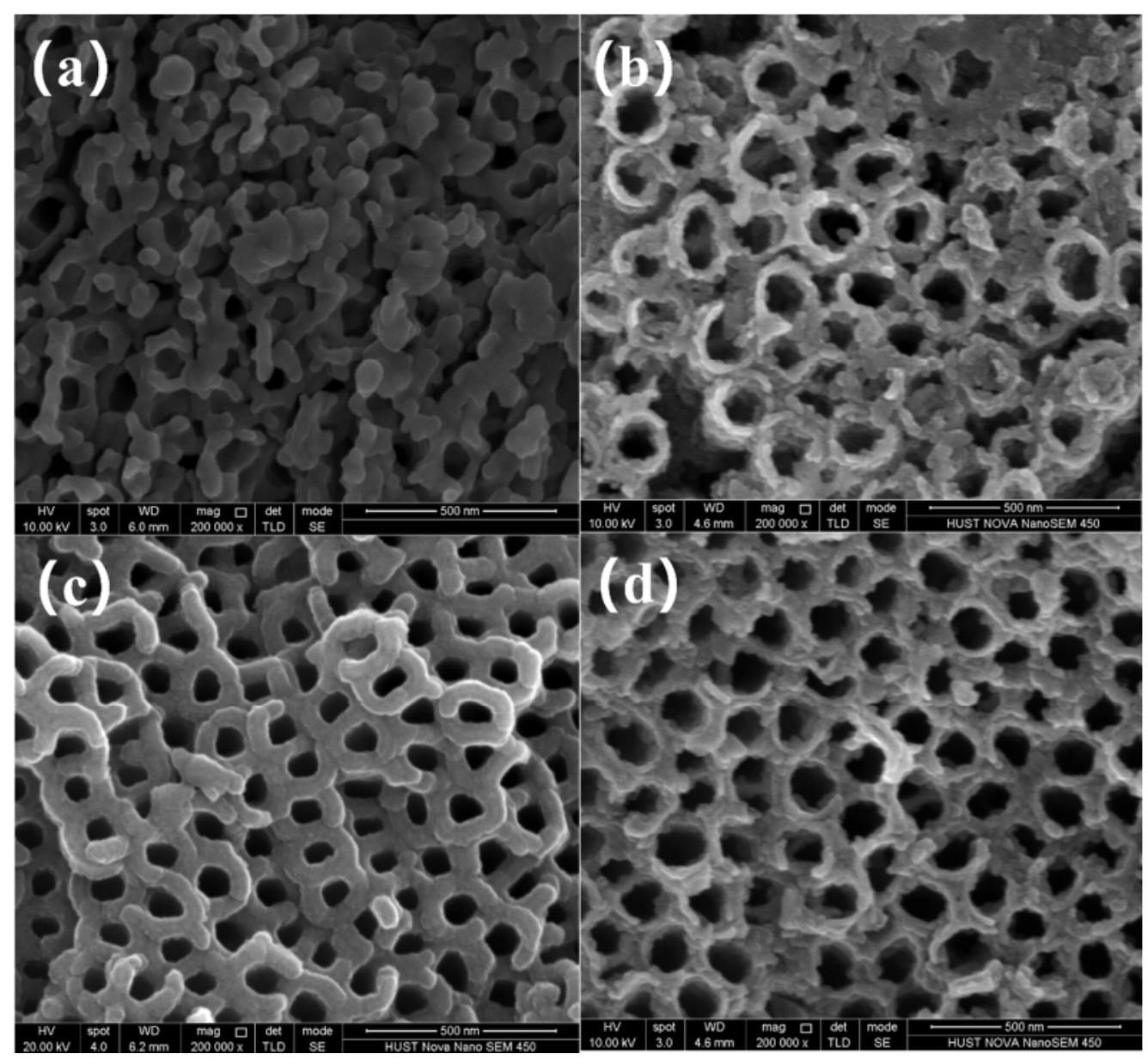

Fig. 8. SEM images of $\mathrm{S} / \mathrm{PPy} / \mathrm{TiO}_{2} \mathrm{NTs}-160$ sample before (a) and after (b) the $100^{\text {th }}$ cycling and $\mathrm{S} / \mathrm{PPy} / \mathrm{TiO}_{2} \mathrm{NTs}^{-}$ 300 sample before (c) and after (d) the $100^{\text {th }}$ cycling

\section{Conclusion}

The $\mathrm{PPy} / \mathrm{TiO}_{2}$ nanotube arrays with coaxial heterogeneous structure have been designed as sulfur 
hosts for lithium sulfur cells. The $\mathrm{TiO}_{2} \mathrm{NTs}$ and PPy were fabricated and combined by means of electrochemical methods, and then underwent a heat treatment with sulfur at different temperatures. The highly ordered array was proven to be effective for confining sulfur inside the nanotubes and to provide an effective pathway for electron transport. Moreover, the elastic PPy layers could alleviate the volumetric expansion of the sulfur and its fluffy structure made the formation of C-S bonds easier. The synergistic effects of $\mathrm{TiO}_{2} \mathrm{NTs}$ and PPy brought about a good electronically conductive framework and alleviated PS dissolution into the electrolyte. Besides, through changing the heat treatment temperature of the cathode, high capacities and Coulombic efficiency could be obtained. Apart from the effect of the microstructure improvement, we also believed that the high temperature of the heat treatment could break down the $S_{8}$ molecule to $S_{6}$ or $S_{2}$ and promote the formation of C-S bonds. This hypothesis was also indicated by the cyclic voltammetry, charge/discharge behaviour, and the TGA, FT-IR and Raman results presented in this study. The S/PPy/TiO 2 NTs-300 cathode exhibited good cycling stability, high Coulombic efficiency and good rate capability. We believe such structures can be applicable for various electrode materials with other active substances. We are still performing further studies based on this structure to optimize the performance of the electrodes.

\section{Acknowledgements}

This work was financed by the Marie Curie IIF Fellowship (623733), the Special Found for Strategic Emerging Industry Development of Shenzhen (JCYJ20120618100557119). Technical assistance from the Analytical and Testing Centre of HUST is gratefully acknowledged. 


\section{Supporting Information}

Experimental details and additional figures showing the EDS analysis, FESEM images of S/PPy/ $\mathrm{TiO}_{2}$ NTs-300, XRD patterns of Ti plate, $\mathrm{PPy} / \mathrm{Ti}$, element sulfur, pure $\mathrm{TiO}_{2} \mathrm{NTs}, \mathrm{S} / \mathrm{TiO}_{2} \mathrm{NTs}$, $\mathrm{S} / \mathrm{PPy} / \mathrm{TiO}_{2} \mathrm{NTs}-160$ and $\mathrm{S} / \mathrm{PPy} / \mathrm{TiO}_{2} \mathrm{NTs}-300$, cyclic voltammograms of $\mathrm{S} / \mathrm{TiO}_{2} \mathrm{NTs}$ in range of 1.5-3.0 V and cyclic voltammetry scan of $\mathrm{S} / \mathrm{TiO}_{2} \mathrm{NTs}$, S/PPy/TiO 2 NTs-160 and $\mathrm{S} / \mathrm{PPy} / \mathrm{TiO}_{2} \mathrm{NTs}^{-}$ 300 cathodes for first few cycles.

\section{References}

[1] A. Manthiram, Y. Fu, S.-H. Chung, C. Zu, Y.-S. Su, Chemical Reviews, 114 (2014) 11751-11787.

[2] B. Dunn, H. Kamath, J.-M. Tarascon, Science, 334 (2011) 928-935.

[3] J.B. Goodenough, Y. Kim, Chemistry of Materials, 22 (2010) 587-603.

[4] M.S. Whittingham, Chemical Reviews, 104 (2004) 4271-4302.

[5] H. Danuta, Juliusz, Ulam, in, ELECTRIC TECH CORP, United States, 1962.

[6] X. Ji, K.T. Lee, L.F. Nazar, Nat Mater, 8 (2009) 500-506.

[7] L.F. Nazar, M. Cuisinier, Q. Pang, MRS Bulletin, 39 (2014) 436-442.

[8] P.G. Bruce, S.A. Freunberger, L.J. Hardwick, J.-M. Tarascon, Nat Mater, 11 (2012) 19-29.

[9] C. Zhang, H.B. Wu, C. Yuan, Z. Guo, X.W. Lou, Angewandte Chemie International Edition, 51 (2012) 9592-9595.

[10] H.S. Ryu, J.W. Park, J. Park, J.-P. Ahn, K.-W. Kim, J.-H. Ahn, T.-H. Nam, G. Wang, H.-J. Ahn, Journal of Materials Chemistry A, 1 (2013) 1573-1578.

[11] W. Ahn, K.-B. Kim, K.-N. Jung, K.-H. Shin, C.-S. Jin, Journal of Power Sources, 202 (2012) 394399. 
[12] L. Ji, M. Rao, S. Aloni, L. Wang, E.J. Cairns, Y. Zhang, Energy \& Environmental Science, 4 (2011) 5053-5059.

[13] S. Evers, L.F. Nazar, Chemical Communications, 48 (2012) 1233-1235.

[14] X. Ji, L.F. Nazar, Journal of Materials Chemistry, 20 (2010) 9821-9826.

[15] M. Gao, X. Xiong, W. Wang, S. Zhao, C. Li, H. Zhang, Z. Yu, Y. Huang, Journal of Power Sources, 248 (2014) 1149-1155.

[16] N. Jayaprakash, J. Shen, S.S. Moganty, A. Corona, L.A. Archer, Angewandte Chemie International Edition, 50 (2011) 5904-5908.

[17] C. Zu, A. Manthiram, Advanced Energy Materials, 3 (2013) 1008-1012.

[18] J. Guo, Y. Xu, C. Wang, Nano letters, 11 (2011) 4288-4294.

[19] Y. Fu, A. Manthiram, The Journal of Physical Chemistry C, 116 (2012) 8910-8915.

[20] C. Wang, W. Wan, J.-T. Chen, H.-H. Zhou, X.-X. Zhang, L.-X. Yuan, Y.-H. Huang, Journal of Materials Chemistry A, 1 (2013) 1716-1723.

[21] J. Wang, J. Chen, K. Konstantinov, L. Zhao, S.H. Ng, G.X. Wang, Z.P. Guo, H.K. Liu, Electrochimica Acta, 51 (2006) 4634-4638.

[22] F. Wu, J. Chen, L. Li, T. Zhao, R. Chen, The Journal of Physical Chemistry C, 115 (2011) 2441124417.

[23] H. Chen, W. Dong, J. Ge, C. Wang, X. Wu, W. Lu, L. Chen, Scientific Reports, 3 (2013) 1910.

[24] Z. Wei Seh, W. Li, J.J. Cha, G. Zheng, Y. Yang, M.T. McDowell, P.-C. Hsu, Y. Cui, Nat Commun, 4 (2013) 1331.

[25] B. Ding, L. Shen, G. Xu, P. Nie, X. Zhang, Electrochimica Acta, 107 (2013) 78-84.

[26] Q. Li, Z. Zhang, K. Zhang, L. Xu, J. Fang, Y. Lai, J. Li, Journal of Solid State Electrochemistry, 17 
(2013) 2959-2965.

[27] Z. Liang, G. Zheng, W. Li, Z.W. Seh, H. Yao, K. Yan, D. Kong, Y. Cui, ACS Nano, 8 (2014) 52495256.

[28] J. Yan, X. Liu, X. Wang, B. Li, Journal of Materials Chemistry A, 3 (2015) 10127-10133.

[29] X.-B. Yang, W. Zhu, K. Qin, H.-Y. Wang, Electrochimica Acta, 143 (2014) 374-382.

[30] H. Wang, W. Zhu, B. Chong, K. Qin, International Journal of Hydrogen Energy, 39 (2014) 90-99.

[31] N.B. Velhal, N.D. Patil, V.R. Puri, Journal of Electronic Materials, 44 (2015) 4669-4675.

[32] A. Kellenberger, E. Dmitrieva, L. Dunsch, Physical Chemistry Chemical Physics, 13 (2011) 34113420.

[33] J.M. Pope, T. Sato, E. Shoji, N. Oyama, K.C. White, D.A. Buttry, Journal of The Electrochemical Society, 149 (2002) A939-A952.

[34] L. Xiao, Y. Cao, J. Xiao, B. Schwenzer, M.H. Engelhard, L.V. Saraf, Z. Nie, G.J. Exarhos, J. Liu, Advanced Materials, 24 (2012) 1176-1181.

[35] X.-g. Yu, J.-y. Xie, J. Yang, H.-j. Huang, K. Wang, Z.-s. Wen, Journal of Electroanalytical Chemistry, 573 (2004) 121-128.

[36] A.J.G. Zarbin, M.-A. De Paoli, O.L. Alves, Synthetic Metals, 99 (1999) 227-235.

[37] Y.-C. Liu, B.-J. Hwang, W.-J. Jian, R. Santhanam, Thin Solid Films, 374 (2000) 85-91.

[38] F. Chen, J. Zhang, F. Wang, G. Shi, Journal of Applied Polymer Science, 89 (2003) 3390-3395.

[39] Y. Cao, X. Li, I.A. Aksay, J. Lemmon, Z. Nie, Z. Yang, J. Liu, Physical Chemistry Chemical Physics, 13 (2011) 7660-7665.

[40] J.A. Korpiel, R.D. Vidic, Environmental Science \& Technology, 31 (1997) 2319-2325.

[41] J. Yan, B. Li, X. Liu, Nano Energy, 18 (2015) 245-252. 
[42] L. Wang, Y. Wang, Y. Xia, Energy \& Environmental Science, 8 (2015) 1551-1558. 